\title{
DETERMINING THE RISK OF DISEASE BASED ON BODY MASS INDEX IN HIGHER EDUCATION
}

\author{
Ionuț CORLACI ${ }^{1}$, Adina GEAMBAȘU ${ }^{2}$, Oana IONESCU²*, Ana Maria GAVOJDEA ${ }^{1}$ \\ ${ }^{1}$ National University of Physical Education and Sport, Faculty of Physical Education and Sport, Bucharest, \\ Romania \\ ${ }^{2}$ National University of Physical Education and Sport, Faculty of Physical Therapy, Bucharest, Romania \\ *Corresponding author: oanac.ionescu@yahoo.com
}

https://doi.org/10.35189/dpeskj.2021.60.3.8

\begin{abstract}
At international and national levels, there is a decline in physical activity because technology has become increasingly present in each person's life, as evidenced by the growing interest in new developments in the field. We believe that giving up exercise will lead to increased indicators of growth and development but also to the emergence of health problems. The current paper aims to determine the body mass index (BMI) of students from two universities, one with a sports profile - National University of Physical Education and Sport, and the other, a non-sports profile higher education establishment - National University of Arts, by performing anthropometric measurements such as height and weight. The purpose of this study is to place students in the category corresponding to their body mass index and determine their risk of disease. This experimental research includes 323 first-year students from the two aforementioned universities in Bucharest. The research methods used are: literature review, anthropometric measurements, mathematical and statistical method, graphical method. Analysis of the collected data reveals differences between the students of the two universities. After interpreting the anthropometric data and calculating the body mass index, the study participants were included in the category corresponding to their risk of disease.
\end{abstract}

Keywords: anthropometric data, body mass index, height, weight.

\section{Introduction}

To have a healthy life, every member of society needs to perform a minimum of physical activity. In this regard, Cavill et al. (2001) emphasise the idea that "all young people should participate in physical activity of at least moderate intensity for 1 hour per day" (p. 12).

As for adults, they should practise recreational (leisure) physical activity, which will give them both mental and physical relaxation after a hard day of work. Brown and Frankel (1993) have shown that, for people living in a midsized Canadian city, "physical activity is most strongly associated with leisure satisfaction in the younger age groups" (p. 1). The data collected by these authors highlight that more women than men engage in exercise, which is revealed by the impact of their "participation in leisure physical activity on life satisfaction" (p. 1). According to the findings of this study, "path analysis indicates that leisure satisfaction contributes both directly and indirectly to life satisfaction" (p. 1).

We believe that technology, which is increasingly present in our lives, leads to a decrease in the physical activity of each individual and will implicitly lead to the occurrence of health problems. This is also emphasised by Nigg (2003), who mentions that "technology has contributed to a secular decline in physical activity" (p. 57); however, technical devices should not be seen as an impediment to physical activity but could be used to modify home 
environments in order to reduce sedentary behaviour and facilitate the practice of physical activity on a daily basis.

The presence of technology associated with a poor diet leads to health problems among the population, even from an early age. According to Braneț et al. (2018), "the sedentary lifestyle is a major factor that leads to childhood overweight and implicitly to a low level of physical fitness. Childhood obesity is growing at an alarming pace, which allows us to talk about a real phenomenon of modern society. This phenomenon is recognised nowadays as a pathology that alters the well-being of mankind as well as the social life of individuals" (p. 91).

Matusitz and McCormick (2012) believe that the influence of Internet use by the population in the United States is a major issue for reducing the level of daily physical activity, which causes an increase in obesity among children and adults. If each person realised how important and beneficial physical activity is for the body, then sedentary behaviour and obesity would be reduced and thus the presence of certain diseases among the population would decrease, and the health care costs would be lower (Wang et al., 2004).

In order to prevent the onset of childhood obesity, support efforts are needed to promote public health strategies aimed at increasing the level of physical activity among children by implementing them in schools, families and communities. Goran et al. (1999) think that physical activity should be encouraged through a number of measures such as "policy changes, environmental planning and educational efforts in schools and communities" ( $p$. 518). Thus, the entire population should perform physical activity, and Bensimhon et al. (2006) support the idea that exercise has been considered over time as "an integral component of weight management" (p. 528). Regular exercise helps prevent weight gain and maintain cardiovascular health.

The World Health Organization (2021b) defines obesity as abnormal or excessive fat accumulation that presents a risk to health. This pathology is known to cause the onset of chronic conditions such as cardiovascular disease, diabetes or cancer. Obesity is a major issue for the entire population of the world. At first, obesity appeared only in developed countries, but nowadays it is found that excess weight is also present in lower-income countries. At the same time, it seems that the occurrence of obesity in urban areas has an increased rate compared to rural areas where physical activity is still performed through agricultural work.

We believe that free time has begun to be spent in front of a screen, whether it is a phone, a TV or a personal computer, to which lack of physical activity, an unhealthy diet based on fast-food products and lack of proper rest are added. As Biddle et al. (2014) have pointed out, effective strategies in this regard should "include the involvement of family, behavioural interventions and electronic TV monitoring devices" (p. 182). We also recommend monitoring the time spent in front of a laptop, tablet or phone because reducing it could allow performing physical activity, which would bring important benefits to the physical and mental condition of each person.

Promoting physical activity among the entire population should involve all factors, whether we are talking about political, social, economic and even psychological ones. The World Health Organization (2018) has designed a "Global action plan on physical activity: More active people for a healthier world", which is applicable in the period 2018-2030. It refers to the fact that increased physical activity helps improve the health of the population by 
preventing and treating certain diseases such as stroke or colon cancer but can also contribute to reducing excessive weight and obesity. In addition to health benefits, exercise can help reduce the use of fossil fuels by reducing road traffic. All of this is possible if physical activity becomes a political priority.

The World Health Organization (2018) states that physical activity can take place both at home and at work. The difference lies in the form of activity performed, which can range from walking, cycling or playing sports to active forms of recreation (for example, dance, yoga, tai chi). Any form of physical activity should be regularly performed and have the necessary duration and intensity depending on each person's physical fitness in order to maintain good health.

The benefits of exercise are known but, to have a healthy life without the occurrence of chronic diseases, some recommendations should be followed:

- "most international guidelines recommend a goal of $150 \mathrm{~min} /$ week of moderate-tovigorous intensity physical activity" (Warburton \& Bredin, 2017, p. 541);

- balanced diet;

- proper hydration (minimum 2 litres of fluids/day);

- sleeping 8 hours/night;

- giving up vices (tobacco, alcohol);

- maintaining a positive attitude;

- relaxation through hobbies (reading, gardening etc).

The World Health Organization (2010) recommends for adults aged 18-64 to engage in physical activity that includes leisure (such as walking, swimming, dancing, etc. or hobbies such as gardening), transportation (walking or cycling), occupational (at work) or household activities (dishwashing, dusting) and different sports, games or planed exercise in the context of daily, family and community activities.

The recommendations of the World Health Organization (2010) on the physical activity of healthy adults are:

- Adults aged 18-64 years should perform at least 150 minutes of moderate-intensity aerobic exercise during the week or 75 minutes of vigorous-intensity aerobic exercise during the week or an equivalent combination of moderate- and vigorous-intensity exercise;

- Aerobic activity should be performed in bouts lasting at least 10 minutes each;

- Muscle-strengthening activities should engage major muscle groups and be performed at least twice a week;

- Adults should increase their moderate-intensity aerobic physical activity to $300 \mathrm{~min} /$ week for additional health benefits.

The American Heart Association (2018) has developed a set of recommendations for both children and adults to perform physical activity. The recommendations for adults are:

- Be active at least $300 \mathrm{~min} /$ week to gain even more benefits;

- Gradually increase amount and intensity over time;

- Spend less time sitting; even light-intensity activity can counterbalance the risk of being sedentary; 
- Get at least $150 \mathrm{~min} /$ week of moderate-intensity aerobic activity or $75 \mathrm{~min} /$ week of vigorous aerobic activity or a combination of both, which should be spread throughout the week, if possible;

- Add moderate- to high-intensity muscle-strengthening activity (for instance, resistance or weights) on at least 2 days/week.

For children, the recommendations of the American Heart Association (2018) are:

- Include vigorous-intensity activity on at least 3 days/week;

- Include muscle- and bone-strengthening (weight-bearing) activities on at least 3 days/ week;

- Gradually increase amount and intensity over time;

- Children aged 3-5 years should be physically active and have a lot of opportunities to move throughout the day;

- Children aged 6-17 years should get at least 60 minutes/day of moderate- to vigorousintensity physical activity, mostly aerobics.

To highlight the state of health, we believe that the body mass index should be calculated because it indicates the risk of overweight in adult people.

The World Health Organization (2021a) states that the body mass index (BMI), which has long been called the Quetelet index, is used to measure nutritional status in adults and calculate their risk of disease. This index was created in the mid-19th century by Adolphe Quetelet, but the modern term "body mass index" first appeared in a paper by Keys et al. (1972), who promoted Quetelet's BMI as the best index of obesity.

Nuttall (2015) says that "the body mass index (BMI) is the metric currently in use for defining anthropometric height/weight characteristics in adults and for classifying (categorizing) them into groups. The common interpretation is that it represents an index of an individual's fatness. It is also widely used as a risk factor for the development of or the prevalence of several health issues. In addition, it is widely used in determining public health policies" (p. 117).

According to the World Health Organization (2021a), the body mass index is calculated as follows: a person's weight in kilograms is divided by the square of the person's height in meters. The formula of the body mass index is: $\mathrm{BMI}=\mathrm{kg} / \mathrm{m}^{2}$. However, the body mass index is calculated taking into account only the height and weight of a person without considering the level of adipose tissue by gender and age or the level of physical activity that any adult should perform on a daily basis to be in good health. In order to highlight more clearly the presence of adipose tissue in a person's body, the body mass index should be associated with other anthropometric measurements such as determination of skinfolds with a calliper, ultrasound adipometry or Bod Pod measurement.

The nutritional status of each individual is a psychosocial problem that, depending on time and culture, has been embodied by the male or female ideal illustrated through art. Nuttall (2015) states that 'traditionally, a person's fatness has been defined at a personal level as well as at a societal level" (p. 117), which emphasises that each individual has a different perception of the constitutional typology. For example, men deposit adipose tissue in the trunk area, while women deposit adipose tissue in the thigh and buttock areas. 
Murguía-Romero et al. (2012) believe that it is important "to analyze the body mass index (BMI) as an indicator of metabolic alterations, including the metabolic syndrome (MetS), at both individual level and public health level" (p. 59).

The purpose of the current paper is to place the research participants in the category corresponding to their body mass index and determine their risk of disease.

Research question: Does regular physical activity help reduce the risk of disease in students?

\section{Methodology}

\section{Participants}

The research group consists of students from two universities as follows:

- National University of Physical Education and Sport, Faculty of Physical Education and Sport - 101 participants; Faculty of Physical Therapy - 116 participants;

- National University of Arts - 106 participants.

The groups of students included in the research were created on the basis of inclusion and exclusion criteria.

The inclusion criteria were: practising any form of physical activity 2-3 times a week for up to 60 minutes; aged over 19 years; first-year students; consent to participate in the research.

The exclusion criteria were: low interest in practising any form of physical activity; aged less than 19 years; lack of consent to participate in the research; previous participation in similar research.

\section{Methods}

- literature review - for documentation on the topic addressed;

- anthropometric measurements:

- body height - is the distance between the vertex and the sole (basis) (Cordun, 2009) with body standing on a flat surface and fully extended, which is measured using a stadiometer. Measurement conditions: in the standing position, touching the stadiometer with the heels, buttocks, shoulder blades and opistocranium (external occipital protuberance). The chin is lowered to the chest, and the gaze is horizontal so that the imaginary line (Frankfurt line) joining the upper edge of the orbit is perpendicular to the graduated rod of the stadiometer. The stadiometer slider stops at the vertex, which is the highest point of the body. The participant's height is read on the graduated rod (Cordun, 2009). Height should be measured in the morning to avoid physiological variations caused by compressive forces on the intervertebral discs;

- body weight - is the sum weight of the structures that make up the body (Cordun, 2009) and is measured by weighing the participant with a digital or mechanical scales. Measurement conditions: stepping on the scales in an upright position with the lower limbs slightly apart, but first the following rules must be observed: the measurement 
will be performed in the morning before breakfast, after evacuation of the digestive tract and bladder; the participant will be dressed briefly (shorts and T-shirt/swimsuit); - body mass index (BMI) - was calculated based on the data collected from the two measurements (height and body weight) by applying the formula: body weight $(\mathrm{kg}) /$ square of body height $\left(\mathrm{m}^{2}\right)$;

- mathematical and statistical method - contributes to detecting possible differences between the investigated groups (one-way ANOVA and independent $t$ test were used);

- graphical method - highlights, with the help of figures/diagrams, the classification of participants in a certain category (underweight, normal weight, overweight, obesity).

\section{Procedure}

The research was conducted in May 2019. All participants were tested under the same conditions and using the same anthropometric devices. A stadiometer made by the "ADE Germany" Company was used to measure height, and a digital scales made by the "Heinner" Company was used to measure weight.

\section{Results}

Data analysis for the investigated group highlights the results presented below. Thus, Table 1 shows the data obtained from the measurement of participants' height.

Table 1. Height measurement

\begin{tabular}{|c|c|c|c|c|c|}
\hline \multicolumn{4}{|c|}{ National University of Physical Education and Sport } & \multirow{2}{*}{\multicolumn{2}{|c|}{ National University of Arts }} \\
\hline $\begin{array}{r}\text { Faculty of Physic } \\
\text { Sp }\end{array}$ & al Education and & Faculty of $\mathrm{Ph}$ & ical Therapy & & \\
\hline $\begin{array}{c}\text { Maximum value } \\
(\mathrm{m}) \\
2.04\end{array}$ & $\begin{array}{c}\text { Minimum value } \\
(\mathrm{m}) \\
1.63\end{array}$ & $\begin{array}{c}\text { Maximum value } \\
(\mathrm{m}) \\
1.98\end{array}$ & $\begin{array}{c}\text { Minimum value } \\
(\mathrm{m}) \\
1.51\end{array}$ & $\begin{array}{c}\text { Maximum value } \\
(\mathrm{m}) \\
1.95\end{array}$ & $\begin{array}{c}\text { Minimum value } \\
(\mathrm{m}) \\
1.40\end{array}$ \\
\hline
\end{tabular}

Table 2 specifies the minimum and maximum values resulting from the measurement of participants' weight.

Table 2. Weight measurement

\begin{tabular}{|c|c|c|c|c|c|}
\hline \multicolumn{4}{|c|}{ National University of Physical Education and Sport } & \multirow{2}{*}{\multicolumn{2}{|c|}{ National University of Arts }} \\
\hline Faculty of Physi & Education and & Faculty of $\mathrm{Ph}$ & sical Therapy & & \\
\hline $\begin{array}{c}\text { Maximum value } \\
(\mathrm{kg}) \\
141.5\end{array}$ & $\begin{array}{c}\text { Minimum value } \\
(\mathrm{kg}) \\
56.3\end{array}$ & $\begin{array}{c}\text { Maximum value } \\
(\mathrm{kg}) \\
148\end{array}$ & $\begin{array}{c}\text { Minimum value } \\
(\mathrm{kg}) \\
41\end{array}$ & $\begin{array}{c}\text { Maximum value } \\
(\mathrm{kg}) \\
106\end{array}$ & $\begin{array}{c}\text { Minimum value } \\
(\mathrm{kg}) \\
40\end{array}$ \\
\hline
\end{tabular}


Table 3 shows the body mass index (BMI) calculated for the research participants.

Table 3. Body mass index

\begin{tabular}{cccccc}
\hline \multicolumn{3}{c}{$\begin{array}{c}\text { National University of Physical Education and Sport } \\
\text { Faculty of Physical Education and } \\
\text { Sport }\end{array}$} & Faculty of Physical Therapy & National University of Arts \\
\multicolumn{2}{c}{} & & & & \\
\hline Maximum value & Minimum value & Maximum value & Minimum value & Maximum value & Minimum value \\
$\left(\mathrm{kg} / \mathrm{m}^{2}\right)$ & $\left(\mathrm{kg} / \mathrm{m}^{2}\right)$ & $\left(\mathrm{kg} / \mathrm{m}^{2}\right)$ & $\left(\mathrm{kg} / \mathrm{m}^{2}\right)$ & $\left(\mathrm{kg} / \mathrm{m}^{2}\right)$ & $\left(\mathrm{kg} / \mathrm{m}^{2}\right)$ \\
38.08 & 18.37 & 37.75 & 16.49 & 39.47 & 14.17 \\
\hline
\end{tabular}

Statistical analysis (descriptive statistics) of the collected data highlights the results obtained by students from both universities after calculating their body mass index (Table 4).

Table 4. Descriptive statistics - Body mass index

\begin{tabular}{ccccc}
\hline University & Faculty & Average & $\begin{array}{c}\text { Standard } \\
\text { deviation }\end{array}$ & $\begin{array}{c}\text { Coefficient of } \\
\text { variation }\end{array}$ \\
\hline $\begin{array}{c}\text { National University of } \\
\text { Physical Education and Sport }\end{array}$ & $\begin{array}{c}\text { Faculty of Physical } \\
\text { Education and Sport }\end{array}$ & 24.01 & 3.41 & 14.31 \\
Fational University of Arts & & 22.58 & 3.25 & 14.46 \\
\hline
\end{tabular}

According to the coefficient of variation, the recorded results show that the two groups of students from the sports profile university are homogeneous, while the sample of students from the non-sports profile university is relatively homogeneous.

Considering the inferential statistics, one-way ANOVA and the $t$ test for independent samples were used. One-way ANOVA procedure allowed us to compare the three groups included in the research (Table 5).

Table 5. Statistical data - One-way ANOVA

\begin{tabular}{lccc}
\hline & $\begin{array}{c}\text { National University of Physical Education and Sport } \\
\text { Faculty of Physical Education and Sport }\end{array}$ & Faculty of Physical Therapy & $\begin{array}{c}\text { National University of } \\
\text { Arts }\end{array}$ \\
\hline $\mathrm{F}$ & 5.255 \\
$\mathrm{p}$ & 0.005 \\
& $\mathrm{p}<0.05$ \\
\hline
\end{tabular}

After applying the one-way ANOVA procedure (comparing the three groups included in the research), it has been found that the differences in BMI between the three groups are statistically significant at $\mathrm{p}<0.05$.

By applying the $t$ test (for independent samples), the data collected from the two faculties of the National University of Physical Education and Sport (Table 6) were compared, as well as the data collected from the aforementioned university and the National University of Arts (Table 7). 
Table 6. Statistical data - $t$ test

\begin{tabular}{lcc}
\hline & \multicolumn{2}{c}{ National University of Physical Education and Sport } \\
t-value & Faculty of Physical Education and Sport & Faculty of Physical Therapy \\
p-value & -3.142 & \\
& 0.000 & \\
\hline
\end{tabular}

After the analysis and statistical interpretation of data, it has been concluded that there are significant differences in BMI $(p<0.05)$ between the two faculties of the National University of Physical Education and Sport in Bucharest.

Table 7. Statistical data - $t$ test (testing the difference between the two universities)

\begin{tabular}{lcc}
\hline & $\begin{array}{c}\text { National University of Physical Education } \\
\text { and Sport (both faculties) }\end{array}$ & National University of Arts \\
\hline $\mathrm{t}$-value & 1.750 \\
$\mathrm{p}$-value & 0.040 & \\
& $\mathrm{p}<0.05$ & \\
\hline
\end{tabular}

After the analysis and statistical interpretation of data using the $t$ test, it has been found that there are significant differences in BMI between the two universities.

Figure 1 shows the values recorded by students from the Faculty of Physical Education and Sport. The minimum value is 18.37 , and the maximum value is 38.08 .

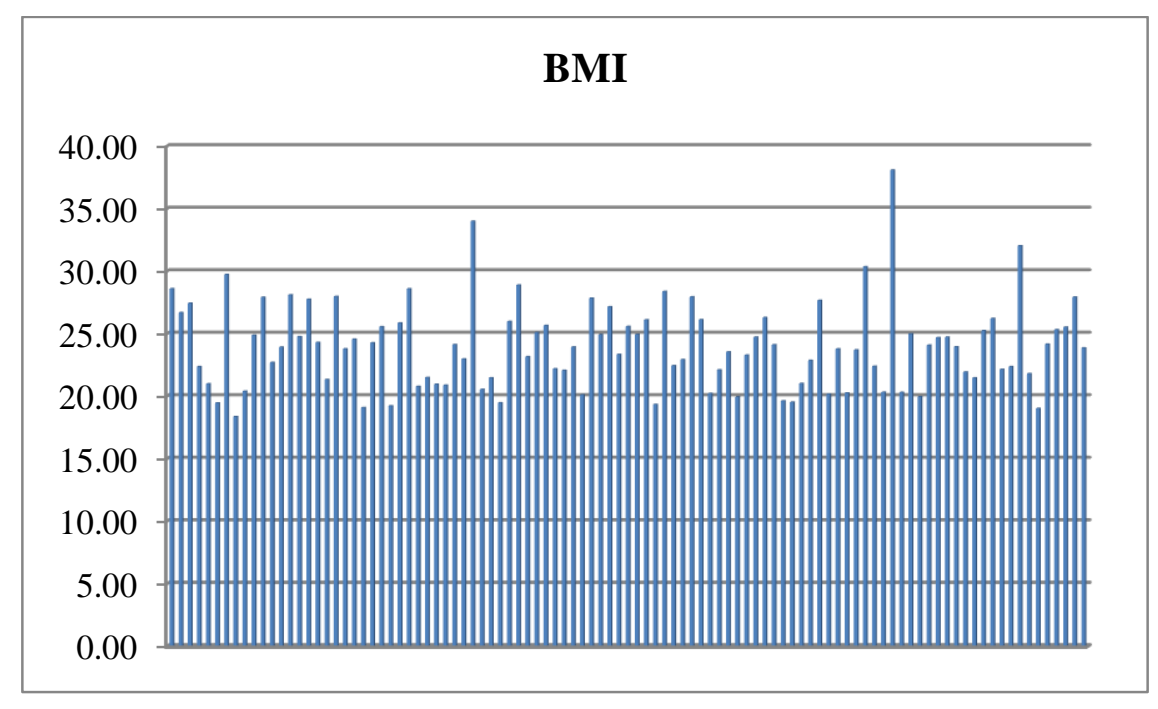

Figure 1. BMI - Students from the Faculty of Physical Education and Sport

Figure 2 highlights the values recorded by students from the Faculty of Physical Therapy. The minimum value is 16.49 , and the maximum value is 37.75 . 


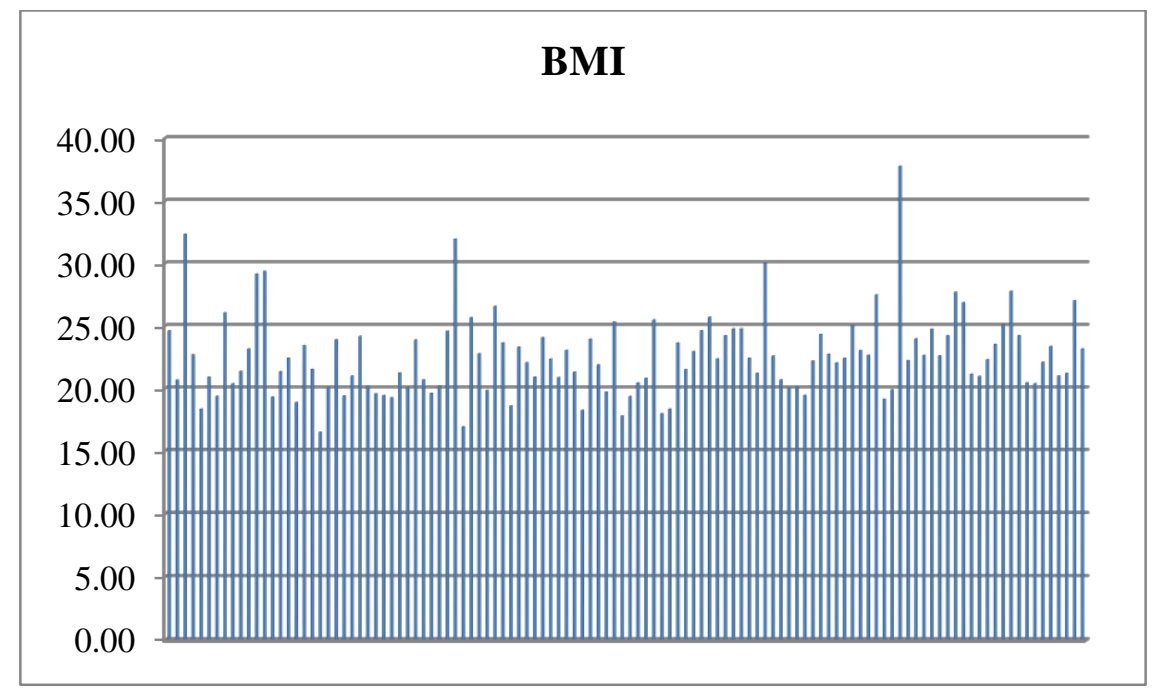

Figure 2. BMI - Students from the Faculty of Physical Therapy

Figure 3 shows the values recorded by students from the National University of Arts. The minimum value is 14.17 , and the maximum value is 39.47 .

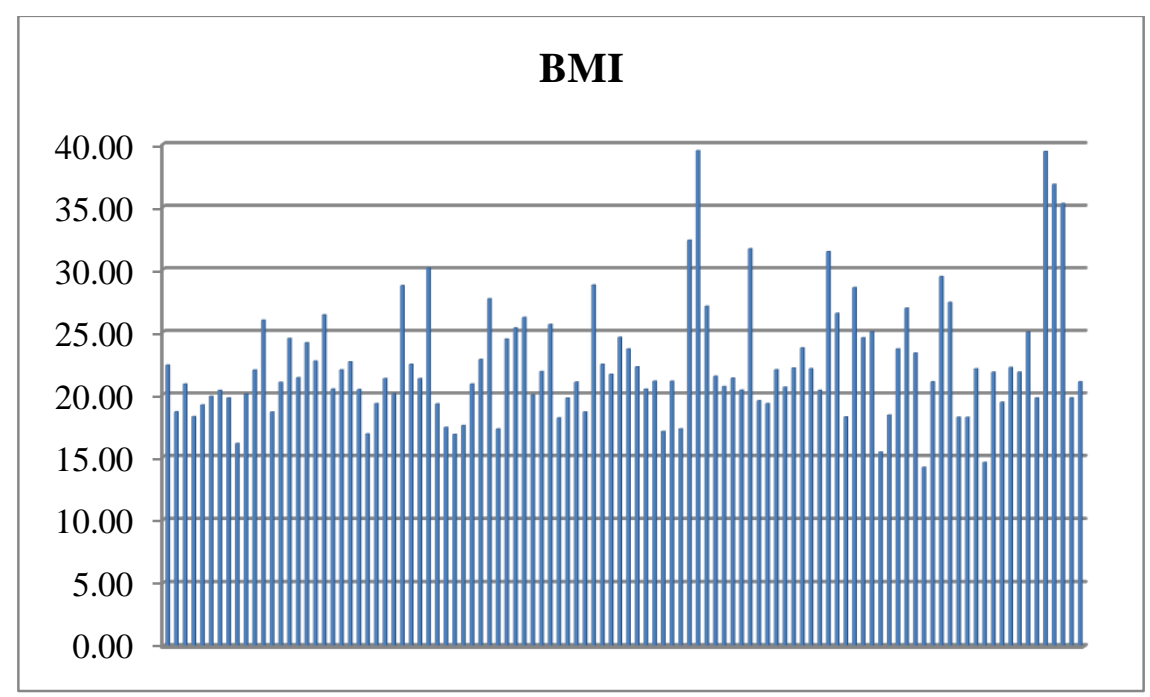

Figure 3. BMI - Students from the National University of Arts

Figure 4 highlights the values recorded by students from the Faculty of Physical Education. Thus, the body mass index is normal for 67 participants, but 29 are in the "overweight" category.

Vulnerability in terms of risk of disease is increased in 34 participants, of which 3 have grade 1 obesity, and 1 has grade 2 obesity. Therefore, $33.6 \%$ of students are at risk of disease. 


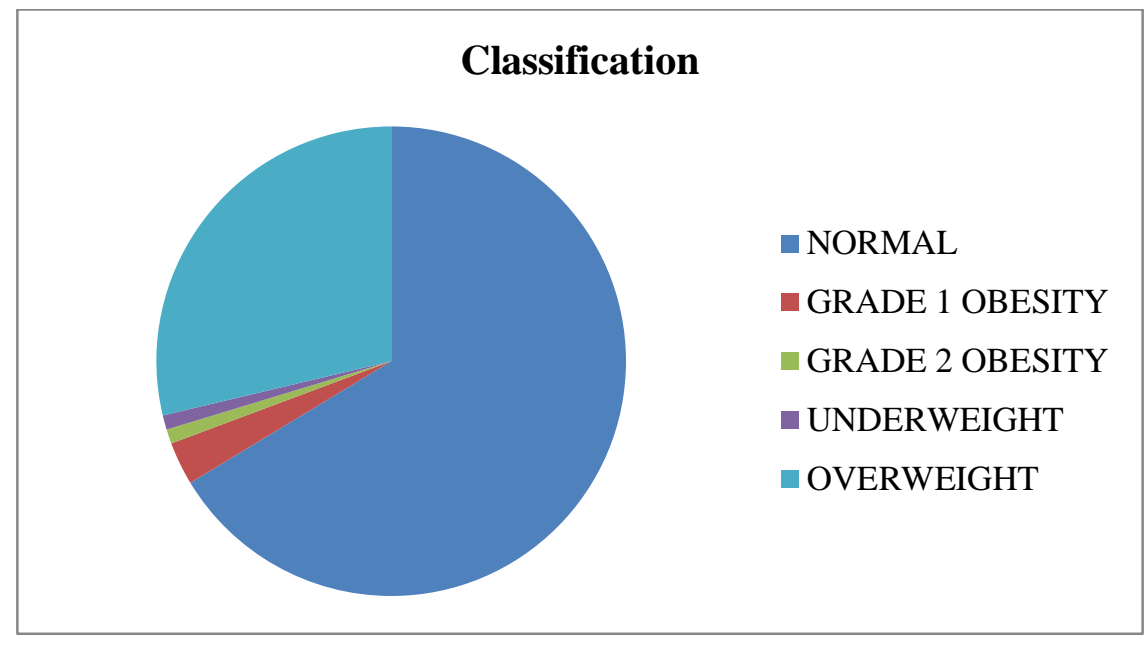

Figure 4. Classification of participants - Faculty of Physical Education and Sport

Figure 5 shows the distribution of participants in the corresponding category after calculating their body mass index. Thus, 90 students from the Faculty of Physical Therapy are within the normal limits of body mass index values $\left(18.5-24.9 \mathrm{~kg} / \mathrm{m}^{2}\right)$, therefore they have the lowest risk of disease. Within the vulnerable categories, there are 7 underweight and 15 overweight students. The 4 subjects with obesity have an increased risk of disease (grade 1 or 2 ). Grade 3 obesity is not found in the group of participants. There are $22.4 \%$ students at risk of disease in the investigated sample.

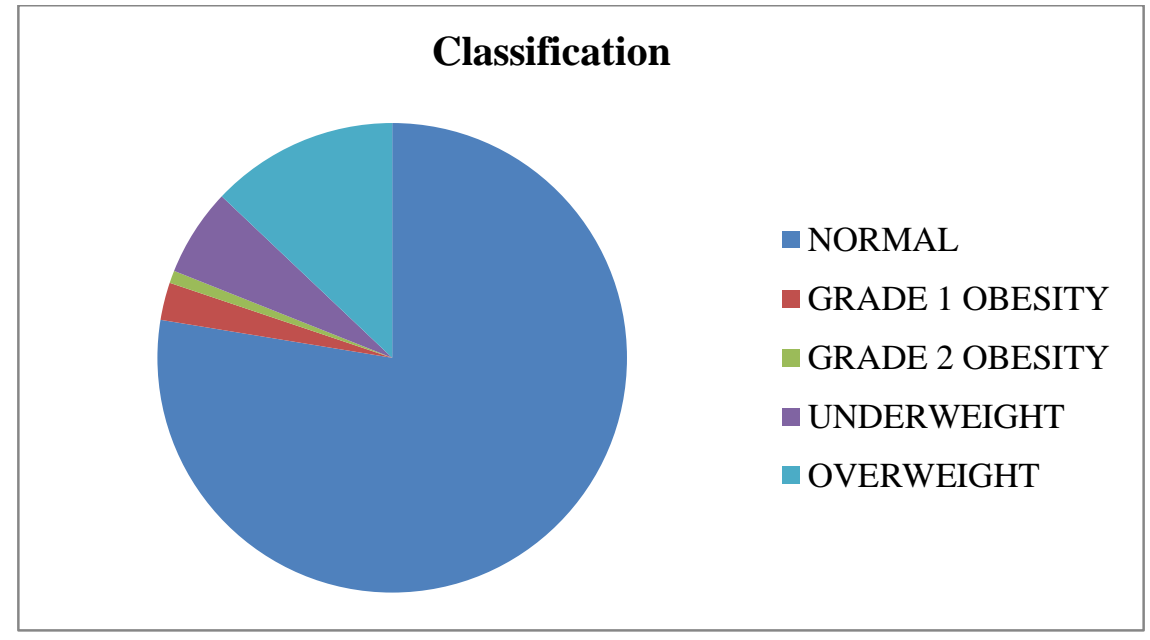

Figure 5. Classification of participants - Faculty of Physical Therapy

Figure 6 shows the distribution of students from the National University of Arts according to their body mass index. Out of a total of 106 participants, 66 fall into the "normal" category, and the 40 participants at high risk of disease are divided as follows: 18 are underweight, 14 are overweight, 4 are included in the "grade 1 obesity" category, and 4, in the "grade 2 obesity" category. Therefore, there are $37.7 \%$ students at risk of disease in the investigated sample. 


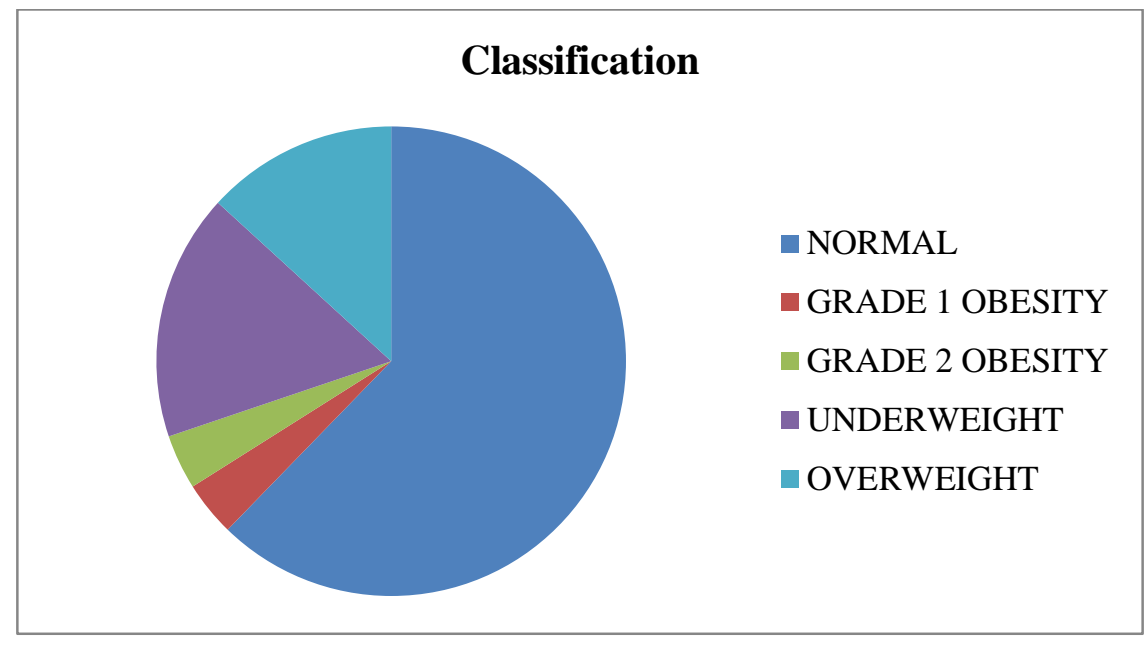

Figure 6. Classification of participants - National University of Arts

\section{Conclusion}

The presence of technology from an early age contributes to an increase in body mass index values for students from both the sports profile university and the non-sports profile university. Technological developments lead to a decrease in physical activity performed in both organised and recreational settings.

The research findings emphasise significant differences in BMI between students from the Faculty of Physical Education and Sport and students from the Faculty of Physical Therapy. There are also significant differences in BMI between students from the National University of Physical Education and Sport and students from the National University of Arts. We mention that the percentage of students at risk of disease from the National University of Physical Education and Sport (both faculties) is $28 \%$ compared to $37.7 \%$ students at risk of disease from the National University of Arts. We can explain this by the fact that, at the Faculty of Physical Education and Sport compared to the National University of Arts, the curriculum includes several sports such as rhythmic gymnastics, artistic gymnastics and acrobatic gymnastics. Thus, first-year students from the sports profile university do more physical activity than first-year students from the non-sports profile university.

Regular physical activity (2-3 sessions/week for about 60 minutes) helps reduce the risk of disease and can influence the level of body mass index. However, we should not forget that, in addition to physical activity, we should change our lifestyle.

In order to reduce the risk of disease, adults should have a balanced diet that provides the necessary intake of vitamins and minerals but also a proper hydration of the body.

Sedentary behaviour will lead to increased obesity among people aged 19-65 years. In turn, obesity will entail the need for medical care.

Quality of life will be negatively influenced by lack of physical activity during childhood, adolescence and adulthood. To improve living conditions, people should be trained to change their behaviour regarding the way of performing individual and collective physical activities. 


\section{Authors' Contributions}

All authors have equally contributed to this study.

\section{References}

American Heart Association. (2018). Recommendations for physical activity in adults and kids. https://www.heart.org/en/healthy-living/fitness/fitness-basics/aha-recs-for-physicalactivity-in-adults

Bensimhon, D. R., Kraus, W. E., \& Donahue, M. P. (2006). Obesity and physical activity: A review. American Heart Journal, 151(3), 598-603. https://doi.org/10.1016/j.ahj.2005.03.005

Biddle, S. J. H., Petrolini, I., \& Pearson, N. (2014). Interventions designed to reduce sedentary behaviours in young people: A review of reviews. British Journal of Sports Medicine, 48(3), 182-186. https://doi.org/10.1136/bjsports-2013-093078

Branet, C., Pelin, R., \& Wesselli, T. (2018). Study on the relationship between BMI and vertical jump in children. The European Proceedings of Social \& Behavioural Sciences, 36, 91-100. http://dx.doi.org/10.15405/epsbs.2018.03.12

Brown, B. A., \& Frankel B. G. (1993). Activity through the years: Leisure, leisure satisfaction, and life satisfaction. Sociology of Sport Journal, 10(1), 1-17. https://doi.org/10.1123/ssj.10.1.1

Cavill, N., Biddle, S., \& Sallis, J. F. (2001). Health enhancing physical activity for young people: Statement of the United Kingdom Expert Consensus Conference. Pediatric Exercise Science, 13(1), 12-25. https://doi.org/10.1123/pes.13.1.12

Cordun, M. (2009). Kinantropometrie. [Kinanthropometry]. CD Press.

Goran, M. I., Reynolds, K. D., \& Lindquist, C. H. (1999). Role of physical activity in the prevention of obesity in children. International Journal of Obesity, 23(Suppl 3), S18-S33. https://doi.org/10.1038/sj.ijo.0800880

Keys, A., Fidanza, F., Karvonen, M. J., Kimura, N., \& Taylor, H. L. (1972). Indices of relative weight and obesity. Journal of Chronic Diseases, 25(6-7), 329-343. https://doi.org/10.1016/0021-9681(72)90027-6

Matusitz, J., \& McCormick. J. (2012). Sedentarism: The effects of Internet use on human obesity in the United States. Journal Social Work in Public Health, 27(3), 250-269. https://doi.org/10.1080/19371918.2011.542998

Murguía-Romero, M., Jimenez-Flores, R., Villalobos-Molina, R., Mendoza-Ramos, M. I., Reyes-Reali, J., Sigrist-Flores, S., \& Rene Méndez-Cruz, A. (2012). The body mass index (BMI) as a public health tool to predict metabolic syndrome. Journal of Preventive Medicine, 2(1), 59-66. http://dx.doi.org/10.4236/ojpm.2012.21009

Nigg, C. R. (2003). Technology's influence on physical activity and exercise science: The present and the future. Psychology of Sport and Exercise, 4(1), 57-65. https://doi.org/10.1016/S1469-0292(02)00017-1

Nuttall, F. Q. (2015). Body mass index: Obesity, BMI and health: A critical review. Nutrition Today, 50(3), 117-128. https://doi.org/10.1097/nt.0000000000000092

Wang, F., McDonald, T., Champagne L. J., \& Edington, D. W. (2004). Relationship of body mass index and physical activity to health care costs among employees. Journal of Occupational and Environmental Medicine, 46(5), 428-436.

https://doi.org/10.1097/01.jom.0000126022.25149.bf 
Warburton, D. E. R., \& Bredin, S. S. D. (2017). Health benefits of physical activity: A systematic review of current systematic reviews. Current Opinion in Cardiology, 32(5), 541-556. https://doi.org/10.1097/hco.0000000000000437

World Health Organization. (2021a). Body mass index - BMI. https://www.euro.who.int/en/health-topics/disease-prevention/nutrition/a-healthylifestyle/body-mass-index-bmi

World Health Organization. (2018). Global action plan on physical activity 2018-2030: More active people for a healthier world. https://apps.who.int/iris/bitstream/handle/10665/272722/9789241514187-eng.pdf

World Health Organization. (2010). Global recommendations on physical activity for health. https://www.who.int/dietphysicalactivity/global-PA-recs-2010.pdf

World Health Organization. (2021b). Obesity.

http://www.emro.who.int/health-topics/obesity/ 